\title{
Cancer quasispecies and stem-like adaptive aneuploidy
}

\section{[version 1; peer review: 2 approved]}

\section{Domenico Napoletani ${ }^{1}$, Michele Signore², Daniele C Struppa ${ }^{3}$}

${ }^{1}$ Institute for Quantum Studies, Chapman University, Orange, CA, 92866, USA

2Department of Hematology, Oncology and Molecular Medicine, Tumor Stem Cell Biobank, Istituto Superiore di Sanita, 00161, Rome, Italy

${ }^{3}$ Schmid College of Science and Technology, Chapman University Chapman University, Orange, CA, 92866, USA

V1 First published: 06 Dec 2013, 2:268

https://doi.org/10.12688/f1000research.2-268.v1

Latest published: 06 Dec 2013, 2:268

https://doi.org/10.12688/f1000research.2-268.v1

\section{Abstract}

In this paper we develop a theoretical frame to understand selfregulation of aneuploidy rate in cancer and stem cells. This is accomplished building upon quasispecies theory, by leaving its formal mathematical structure intact, but by drastically changing the meaning of its objects. In particular, we propose a novel definition of chromosomal master sequence, as a sequence of physically distinct whole or fragmented chromosomes, whose length is taken to be the sum of the copy numbers of each whole or fragmented chromosome. This fundamental change in the functional objects of quasispecies theory allows us to show that previously measured aneuploidy rates in cancer populations are already close to a formally derived aneuploid error threshold, and that any value of aneuploidy rate larger than the aneuploid error threshold would lead to a loss of fitness of a tumor population. Finally, we make a phenomenological analysis of existing experimental evidence to argue that single clone cancer cells, derived from an aneuploid cancer subpopulation, are capable of self-regulating their aneuploidy rate and of adapting it to distinct environments, namely primary and metastatic microenvironments. We also discuss the potential origin of this selfregulatory ability in the wider context of developmental and comparative biology and we hypothesize the existence of a diversification factor, i.e. a cellular mechanism that regulates adaptation of aneuploidy rates, active in all embryo, adult and cancer stem cells.

\section{Keywords}

Chromosomal instability; Aneuploidy; Cancer; Stem Cells;

Quasispecies; Error Threshold

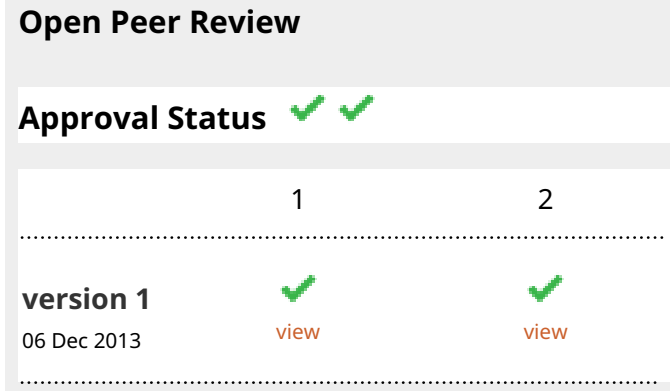

1. Jan Oxholm Gordeladze, University of Oslo, Oslo, Norway

2. Samuel F Bakhoum, Harvard Medical School Boston, MA, USA

Any reports and responses or comments on the article can be found at the end of the article. 
Corresponding author: Domenico Napoletani (napoleta@chapman.edu)

Competing interests: No competing interests were disclosed.

Grant information: The author(s) declared that no grants were involved in supporting this work.

Copyright: @ 2013 Napoletani D et al. This is an open access article distributed under the terms of the Creative Commons Attribution License, which permits unrestricted use, distribution, and reproduction in any medium, provided the original work is properly cited.

How to cite this article: Napoletani D, Signore M and Struppa DC. Cancer quasispecies and stem-like adaptive aneuploidy [version 1; peer review: 2 approved] F1000Research 2013, 2:268 https://doi.org/10.12688/f1000research.2-268.v1

First published: 06 Dec 2013, 2:268 https://doi.org/10.12688/f1000research.2-268.v1 


\section{Introduction}

In normal cells the number of chromosomes and the total DNA content depends on the phase of the cell cycle ${ }^{1}$. Non-diploid chromosome content, also known as aneuploidy, is instead the most common feature of human tumor cells ${ }^{2-4}$. This feature of tumor cells is commonly associated with acquired resistance to various kinds of treatments such as radio- or chemotherapy ${ }^{2-5}$. Nonetheless, it is not completely clear whether aneuploidy per se contributes to and drives tumor development, or if instead it is deleterious. In fact, individuals carrying an extra copy of chromosome 21 have a $50 \%$ lower probability of developing solid tumors than do individuals with the correct chromosome number ${ }^{6,7}$ and although aneuploidy is compatible with organism and cell viability, the presence of additional copies of chromosomes decreases the overall cellular fitness ${ }^{8}$. What is clear is that chromosomal instability, i.e. the tendency to gain or lose parts of the genome during cell replication, seems to give an advantage to tumor cells ${ }^{9}$, and clonal heterogeneity within tumors is one of the main causes of tumor dormancy and resistance to anti-cancer therapies ${ }^{5,10}$. Indeed, it has been demonstrated that even a small population of cells derived from a single cancer cell clone (diversified population from a single cell), could be responsible for drug resistance and, upon removal of the drug, the population spontaneously reverted to a sensitive state ${ }^{11,12}$.

The development of single-cell sequencing techniques ${ }^{13}$ has recently allowed a wide range of studies analyzing chromosomal variability in primary and metastatic tumor cells, as well as healthy tissues ${ }^{14,15}$. In particular in Navin et al. ${ }^{16}$ it is shown that metastatic tumors are likely to be the product of single clones proliferating from the primary tumor by observing the microvariation of the integer copy number of consensus sequences in individual tumor cells through single-cell sequencing.

In this paper we are concerned with measurable changes in the aneuploid heterogeneity of populations, due to different levels of chromosomal instability, and to emphasize even more the close link between aneuploidy and chromosomal instability. We will refer to the latter as aneuploidy rate, formally defining aneuploidy rate as the average probability that there is at least one new aneuploid modification per chromosome during cell replication. We will demonstrate in the Discussion that simple and verifiable statistical consequences of the findings of Navin et al. ${ }^{16}$ are logically bound to imply the following proposition.

Adaptive Aneuploidy in Cancer Cells: Single clone cancer cells derived from an aneuploid cancer subpopulation are capable of adapting their aneuploidy rate and display distinct aneuploid rates in distinct environments, namely primary and metastatic microenvironments.

The full impact of this proposition hinges on the potential ability to harness adaptive aneuploidy and potentially alter the aneuploidy rate of cancer cells. The theoretical frame for such a program can be built on quasispecies theory, a general evolutionary model for error-prone self replicative systems ${ }^{17}$, first introduced by Eigen ${ }^{18}$. The potential relevance of quasispecies theory to cancer biology has already been suggested ${ }^{19,20}$ but unlike previous attempts ${ }^{20-26}$, we do not recommend in this paper alternative, structurally diffnt quasispecies models of cancer cell subpopulations dynamics. Instead, after a quick review of the relevant elements of standard quasispecies theory, we note the limits of this theory for the study of eucaryotic cells, and show that only by defining a novel notion of chromosomal master sequence it is possible to radically shift the whole standard quasispecies theory to a new categorical context (i.e. the scenario of cell populations with variable aneuploidy rates) and properly justify a valid aneuploid quasispecies theory. This new context allows us to predict (similarly to what the standard quasispecies theory does for single base error rates) a maximal aneuploidy rate, an error threshold, after which each cancer subpopulation loses its identity, and therefore its ability to pass on its selectively advantageous genetic traits to future cell generations, which is referred to as error catastrophe ${ }^{27}$.

Finally, in the Discussion we perform a phenomenological analysis of some especially illuminating single cell analysis experiments, from Navin et al. ${ }^{16}$, that seem to support our proposition on the existence of adaptive aneuploidy in cancer cells. We then speculate on the possible biological basis of self-regulation of aneuploidy rates in cancer cells. Such refined ability is unlikely to be the product of a single, specific tumor evolutionary history, rather, we will argue that embryo and adult stem cells already display very finely regulated rates of aneuploidy, suggesting that a common cellular mechanism of adaptation of aneuploidy is at play, a diversification factor, which is possibly reactivated in cancer stem cells.

\section{Aneuploid quasispecies}

\section{The quasispecies framework}

As noted in the Introduction, we need to redefine the main quantities at play in quasispecies theory to make it an appropriate ground for the biology of aneuploidy, and we begin by briefly sketching the argument that leads to the error threshold inequality.

The concept of quasispecies was first introduced by Eigen ${ }^{18,28}$, and it is a powerful way to relate the structure of population dynamics to the error rate of single base replication in viruses or unicellular organisms ${ }^{27,29}$. The most important consequence of the theory is that it is possible to determine theoretically a threshold on the error rate such that, if the error rate of replication of genomic sequences is pushed above the threshold, the subpopulation will not be able to retain its identity, for a wide range of models for fitness distribution in the population (cf. Schuster ${ }^{30}$, page 81 ).

Assuming there are $N$ subpopulation types within a population, we start by writing down the differential equation that describes the rate of change $d x_{m}$ of type $m$ in terms of the instantaneous size $x_{k}(t)$, $k=1, \ldots, N$ of all types:

$$
\frac{d x_{m}}{d t}=\left(W_{m m}-\bar{E}(t)\right) x_{m}(t)+\sum_{k \neq m} W_{m k} x_{k}(t)
$$

$W_{m m}$ is the rate of effective excess production of sub-population type $m$, and if we consider the genetic sequence associated to type $m$, we can write $W_{m m}=Q_{m m A m}-D_{m}$, with $Q_{m m}$ the probability of precise reproduction of sequence $m, A_{m}$ the growth rate of type $m$, and $D_{m}$ its mortality rate. $\bar{E}(t)=\Sigma_{k} E_{k} x_{k}$ is the average, over all types, of the 
excess reproduction rate, with $E_{k}=A_{k}-D_{k}$ and, finally, $W_{m k}$ is the rate of production of type $m$ by erroneous reproduction of type $k$.

Assuming a steady state in which $d x_{m} / d t=0$ and neglecting in first approximation the contributions $\Sigma_{k \neq m}{ }^{m} W_{m k} x_{k}(t)$, it is possible to derive a condition that constrains the probability of precise reproduction of sequence $m$ :

$$
\overline{\boldsymbol{\sigma}}_{m} Q_{m m}>1
$$

where $\bar{\sigma}_{m}=A_{m} /\left(D_{m}+\bar{E}_{k \neq m}\right)$, with $\bar{E}_{k \neq m}=\Sigma_{k \neq m} E_{k} x_{k}$, is the average superiority of a master sequence associated to a dominant subpopulation versus competitor sequences, essentially, $\bar{\sigma}_{m}$ is an index of relative fitness ${ }^{27}$. If a master sequence has length $v_{m}$, and we denote by $\bar{q}$ the average fidelity of single nucleotide reproduction, then $Q_{m m}=\bar{q}^{y}$ and the error threshold can be written as

$$
\frac{\ln \bar{\sigma}_{m}}{v_{m}} \geq 1-\bar{q} .
$$

Remarkably, Equation 3 establishes a phase transition on the information content; if the error rate of single nucleotide reproduction goes above $\frac{\ln \bar{\sigma}_{m}}{v_{m}}$ the information contained in the master sequence will disintegrate, in the sense that the loss of information in the sequence due to reproduction errors will not be compensated by a sufficiently high fitness relative to other subpopulations and the subpopulation associated to the master sequence will implode ${ }^{27,30}$.

\section{Limitations of quasispecies theory in eucaryotic cells}

In complex organisms, the quasispecies model is potentially applicable only in specific scenarios, such as competition among embryo stem cells during development, adult stem cells and progenitor cells proliferation, and, crucially, cancer cells, where subpopulations compete with each other under limited resources and changing environment. However, the applicability of the basic quasispecies model, originally devised in the setting of virus RNA replication, has been put into question as appropriate for eucaryotes and specifically for cancer cells. Eucaryotic cells reproduce semiconservatively meaning that the parental double strand degenerates in the process of generating two daughter double strands, which led to Brumer et al. ${ }^{21}$ to raise the possibility that, for high enough replication error rates, the master sequence, seen here as the double strand of DNA, would eventually disappear, and they suggested more refined quasispecies models that take into consideration this phenomenon.

Even more seriously, the applicability of quasispecies theory to human cells is put into question by the exceedingly high size of the human genome as compared to RNA viruses. In fact, in order for the quasispecies not to undergo genetic drift, the neutral space around a fitness peak should be sufficiently small to be completely explored by the population. The complexity and the inherent mutational and phenotypical robustness of the human genome amplifies its neutral space, preventing quasispecies evolution even at higher than normal mutation rates, as it is the case in cancer cells ${ }^{31}$. This fact, together with very low single nucleotide errors for humans, implies that the fitness of mutants of an hypothetical master sequence does not change significantly, and the fitness distribution of mutants around the master sequence is likely to decay linearly, or sub-linearly, a scenario under which no error threshold is possible ${ }^{30}$.

Indeed, the existence of Lynch syndrome or hereditary nonpolyposis colorectal carcinomas (HNPCC), which are characterized by a higher risk of colon cancer, show the inability of the basic quasispecies theory to predict the maximum single nucleotide error that is viable for a tumor. HNPCC tumors, as well as all microsatellite instable (MSI) colon cancers, arise because of a break down of the mismatch repair mechanism ${ }^{32,33}$. Therefore, MSI cancer cells display increased error rates of single nucleotide replication by 1 to 3 orders of magnitude, with respect to the baseline single nucleotide error rate $1-\bar{q}$ in healthy cells, estimated to range between $10^{-9}$ and $10^{-10}$ for the human genome (see Alberts et al. ${ }^{34}$, page 271, and Gundry \& Vijg ${ }^{35}$, Lange et al. ${ }^{36}$ and Jiricny ${ }^{37}$ ).

Now recall that the human genome has roughly $3.2 \times 10^{9}$ nucleotides (see Alberts et al. ${ }^{34}$, page 206), and note that for organisms with very large genomes, the relative superiority $\bar{\sigma}_{m}$ of a master sequence associated to a given subpopulation cannot be very large (vis a vis other subpopulations), as any given mutation will only affect its fitness marginally ${ }^{27}$, and therefore $\bar{\sigma}_{m} \approx 1$. Given these numerical estimates, according to the error threshold inequality in Equation 3, MSI tumors would fail to satisfy the error threshold inequality to such an extent that they should not even exist. This is true even if we restrict our attention, in defining the master sequence, to conserved DNA, i.e. the $5 \%$ of the human genome that is known to be coding and essential to cell function (see again Alberts et al. ${ }^{34}$, page 206).

\section{Chromosomal master sequences and aneuploid error thresholds}

We believe that the inconsistences of the basic quasispecies model, when applied to human cells, completely disappear if we replace single nucleotide errors with aneuploidy errors. Notably, in all scenarios where quasispecies theory could potentially apply, i.e. stem and progenitor cells proliferation and cancer cells, aneuploidy rates far exceed single nucleotide error rates in frequency and impact on the cell. This means the leading cause in the evolution of a population will be the aneuploidy error, rather than the single nucleotide error, which can be neglected, especially when the mismatch repair genes are intact as happens in the overwhelming majority of cancers and all healthy stem cells.

We need now to reinterpret the notion of reproduction fidelity of a sequence adequately to properly define error thresholds in the presence of aneuploidy. Since we can neglect nucleotide errors, we assume a faithful reproduction of the genetic material when the copy number of each chromosome in a sequence (two, for example, in a diploid cell) is kept constant during replication, both numerically (number of physically distinct whole chromosomes or fragments) and structurally (translocations, deletions and amplifications of DNA). Although complex aneuploidy landscapes may arise, characterized by concurrent numerical and structural chromosomal changes, most of the somatic copy-number alterations (SCNAs) 
frequently found in tumor cells involve whole chromosomes or whole-arms ( $25 \%$ of the genome), with only $10 \%$ of the cancer cell genome being affected by focal SCNAs ${ }^{9,38,39}$.

Therefore, we now make a series of definitions consistent with these arguments, whose objective is to change the domain of applicability of quasispecies theory, without altering its formal mathematical structure:

Chromosomal Master Sequence. A chromosomal master sequence is the collection of physically distinct whole and fragmented chromosomes in the cell.

Chromosomal Master Sequence Length. The chromosomal master sequence length $c_{m}$ of a cell is the sum of the copy numbers of each whole or fragmented chromosome in its nucleus.

Aneuploid Fidelity. The aneuploid fidelity $\bar{A}_{m}$ is the average probability that each whole or fragmented chromosome is reproduced exactly once in cell division, with no gain or loss of sub-chromosomal regions.

In this aneuploid scenario, the chromosomal master sequence length $c_{m}$ can fluctuate depending on the number of aneuploid copies of whole chromosomes or fragments, and the underlying nucleotide sequence will clearly differ according to which chromosomes or individual genes are affected by copy-number alterations in each cell. Although tumors vary widely in the number and type of copy number changes, most of these comprise low-level alterations and only a few genes reach more than 20 copy numbers, mainly due to their oncogenic or drugresistance functions ${ }^{16,40-42}$.

Aneuploid events can cause large phenotypical variations ${ }^{43-46}$, even a single error leading to chromosomal loss or addition can have large effects, therefore the fitness distribution around a master sequence is expected to display a sharp decay from the master sequence peak, in line with the types of fitness distribution known to express the error threshold ${ }^{30}$. At least for cancer cells, subpopulations are sharply defined in terms of their aneuploid profile, as evinced from single cell analysis works ${ }^{16}$ commented in the Discussion. This is further evidence of the strong concentration of fitness distributions around a few chromosomal sequence types.

Mutants of the master sequence, generated by even a single aneuploid error, and individual cells belonging to other sub-populations, are exceedingly unlikely to be able to mutate into cells expressing the master sequence, since any additional (erroneous) chromosome copy is subject to a wide variety of further partial deletions/additions, and only very few of them would correspond to a return to the master sequence configuration. Essentially, we can assume that the contribution of cells belonging to other subpopulation types to the dynamical evolution of the master sequence subpopulation is very small. This is exactly the condition that led to the error threshold in the first place, since Equation 3 is derived as a limiting stationary behavior of an interacting family of subpopulations described by Equation 1, where the rate of growth of each of them is weakly affected by the cross-mutations derived from the other subpopulations ${ }^{27,30}$.
Given these caveats regarding distribution of fitness for chromosomal master sequences in the presence of aneuploidy and regarding sub-population interactions, we reach the conclusion that quasispecies theory is indeed applicable to cancer and stem cells, but only in the context of aneuploid chromosomal master sequences, neglecting the underlying nucleotide errors.

We can now replace variables in the error threshold inequality in Equation 3 to take into account not only the varivariable length $c_{m}$ of the chromosomal master sequence associated to all whole and fragmented chromosomes, but also the correction to the probability $Q_{m m}$ of precise reproduction of a sequence that aneuploidy entails. The probability of precise reproduction of a specific sequence of chromosomes $m$ can be expressed as $Q_{m m}=\bar{A}^{c_{m}}{ }_{m}$, and the aneuploid error threshold inequality can be written as $\bar{\sigma}_{m} \bar{A}^{\underline{m}} c_{m}>1$, which eventually gives us a standard form (formally identical to Equation 3 ) for the aneuploid error threshold inequality:

$$
\frac{\ln \bar{\sigma}_{m}}{c_{m}} \geq 1-\bar{A}_{m},
$$

However each term in this equation has drastically different orders of magnitudes than the threshold inequality for DNA or RNA master sequences. To start with, as already stressed above, the relative superiority $\bar{\sigma}_{m}$ will have considerable fluctuations, since the chromosomal master sequence is much shorter than a nucleotide sequence, and even small variations in copy numbers can effect large phenotypical variations.

At the same time, the diversity of subpopulations in primary tumors ${ }^{16,47-51}$ implies that, in a fully developed tumor, different subpopulations do not have extremely different relative superiority $\bar{\sigma}_{m}$, a scenario that would lead to a single, highly dominant subpopulation. It is therefore reasonable to assume at the very most $\bar{\sigma}_{m} \in\left[10^{2}, 10^{3}\right]$, for the subpopulations of highest relative superiority. We know moreover that highly aneuploid tumors have higher fitness ${ }^{52}$, so larger values of $\bar{\sigma}_{m}$ are likely to be associated with large values of $c_{m}$, up to the order of $10^{213,39,53,54}$.

Let $E_{m}=1-\bar{A}_{m}$, with $E_{m}$ denoting the aneuploidy error rate, i.e. the average probability that there is at least one new aneuploid defect for each chromosome or fragment of chromosome during cell replication. If we call $T\left(E_{m}\right)$ the threshold aneuploidy error rate above which a chromosomal master sequence is not viable, and if we take $\bar{\sigma}_{m} \in\left[10^{2}, 10^{3}\right], c_{m} \approx 10^{2}$, then Equation 4 gives $T\left(E_{m}\right) \approx 10^{-2}$, which is consistent with the estimates of $E_{m}$ for cancer cells, in the range $\left[10^{-3}, 10^{-1}\right]^{3,55-58}$. Our argument implies that the more a cell is aneuploid, the tighter the error threshold bound is, and that highly aneuploid cancer cells, known to be most adaptable ${ }^{5,52,59,60}$, are already working with aneuploid error rates close to the limit of a viable quasispecies.

There is some evidence that indeed aneuploidy rates in the tumor can affect the prognosis of cancer patients ${ }^{9,61}$. It is suggested that a moderate tumor aneuploidy rate worsens the prognosis, while a 
very high aneuploidy rate is associated with improved patient outcomes $^{9}$, consistent with the quasispecies and error threshold catastrophe approach.

\section{Discussion}

We would like to revisit and comment upon some specific experimental evidence for our proposal of a self-regulated aneuploidy rate in cancer cells, focusing on several measures of aneuploidy rate, and showing how the variability observed in tumor subpopulations subject to distinct micro-environments can be given a far-reaching interpretation. Our analysis is phenomenological, meaning that we explain and reinterpret existing experimental work, showing how the inner logic of our argument can severely constraint the causes and interpretation of the data we review. We chose to first perform an in-depth analysis of a single recent study ${ }^{16}$, so that the flow of our discourse is unified and made coherent by constant reference to the same context. At the same time, we support our arguments with related experimental works, when appropriate.

The in-depth analysis and commentary of the literature that we perform here is meant to show that there is rigorous, logically compelling, and experimentally testable biological evidence for the usefulness of an aneuploid quasispecies theory. Indeed, we argue that it is possible to envision a precise, and functionally in-built mechanism of self-regulation for aneuploidy rates in normal and cancer stem cells. The evolutionary role and the structure of this self-regulation mechanism could be studied and conceptualized within the framework we developed for aneuploid quasispecies. At the same time, any experimental validation of aneuploid quasispecies predictions on threshold aneuploidy error rates, would be essentially related to the presence of this self-regulatory mechanism.

Evidence for self-regulation of aneuploidy rates in cancer cells The main focus and objective of Navin et al. ${ }^{16}$ was to show that metastatic tumors are likely to be the product of single clones proliferating from the primary tumor by observing the microvariation of the integer copy number of consensus sequences in individual tumor cells through single-cell sequencing. A coarse ploidy distribution of a large number of cells from a breast tumor and one of its metastasis was plotted in Navin et al. ${ }^{16}$ (Figure 3a-b in that paper) as an histogram with respect to the total DNA content. These ploidy distributions showed, for both primary and metastatic tumors, two peaks, one around twice and another at four times the total amount of DNA. This double peaked distribution is accounted by the presence of roughly $50 \%$ of normal diploid cells in each tumor tissue sample. Importantly, whereas in the primary tumor a significant fraction of the gated normal cells was pseudodiploid, in the paired metastasis the normal population was likely to derive from the stromal content of the tissue (see ref. ${ }^{16}$, Figure 4 in their paper).

Navin et al. ${ }^{16}$ performed very refined measurements of copy number profiles, across all chromosomes, from a small subset of cells (hundreds) in sections of primary and metastatic tumors and generated a neighbor-joining tree of these profiles. This analysis showed that metastatic and primary aneuploid cells were closely related in the neighbor-joining tree derived from the clustering, and yet they produced clearly distinct subclusters. The conclusion of this single cell study was that the metastasis proliferated from a single cell derived from the aneuploid subpopulation of the primary tumor, since no pseudodiploid cancer cells were observed in the metastatic tumor.

Other recent studies on myeloproliferative disorders ${ }^{62}$ and melanoma ${ }^{54}$, kidney $^{47,48}$ and pancreas ${ }^{49}$ tumors or, again, in breast cancer ${ }^{50}$, arrived at similar conclusions, pointing to a late, metastasis-specific diversification of primary tumor-derived cells (see Wu et al. ${ }^{63}$, Figure S14, and Clifford ${ }^{64}$ ). The presence of aneuploid cells in most primary tumors examined in Gerlinger et al. ${ }^{49}$, is well documented by ploidy analysis (see supplementary Figure 10 in their paper) and metastases show a marked increase in allelic imbalance as compared to primary tumor regions. The authors conclude that tumor heterogeneity is probably driven by aneuploidy and that chromosomal aberrations contribute substantially to genetic intratumor heterogeneity. Notably, even in an evolutionary context where the primary tumor and the metastasis share most of the sequenced regions, there is a striking variation in copy number specifically in the metastatic counterpart (see ref..$^{54}$, Figures S5 to S11 in Lengauer et $\left.a l .{ }^{54}\right)$. This concept is best exemplified in ref. ${ }^{16}$, but there, both the coarse ploidy distribution analysis and the refined, single cell copy number count for primary and metastatic tumors, drive us to an additional conclusion: the genetic variability of the aneuploid clone in the metastasis is greater than its corresponding variability in the primary tumor from which it came. Even if we took into account a parallel progression model as opposed to a punctuated or linear evolution model ${ }^{51,65}$, the final result would not change. The metastatic population described in Navin et al. ${ }^{16}$ has diversified more than its parental population in the primary tumor, regardless of whether the metastasis developed in a later, much shorter time than the primary tumor, or whether its origins date back to the first stages of primary tumor dissemination. This higher diversification of the metastatic population holds even though the aneuploid cells' compartment in the primary tumor does not represent a minority of the population, and has expanded considerably at some point during the tumor evolution history.

To justify our claim of adaptive aneuploidy, we note that in Figure 4 of Navin et al. ${ }^{16}$ the Euclidean distances in the neighbor-joining tree for the aneuploid cells from the metastatic tumor showed much greater variability than the Euclidean distances for the corresponding aneuploid cells in the primary tumor. We note that these distances were calculated with respect to a common root profile, and that mutual distances among individual profiles are likely to be ever greater. Granted that this study dealt with very small sample populations, a closer inspection and analysis of the tightness of the variance of Euclidean distances in the primary tumor subpopulation, as opposed to the variance of Euclidean distances of the metastatic tumor subpopulation, would almost certainly reveal a statistically significant discrimination of the two. Indeed, distances inferred from their Figure 4 of ref. ${ }^{16}$ using a Levene test for equality of variance ${ }^{66}$ suggest a low probability that the underlying distributions of Euclidean distances for metastatic aneuploid cells and for primary aneuploid cells have the same variance ( $\mathrm{p}$-value $\approx 0.01$ ).

Note, crucially, that even if we assume high experimental noise in the data, such noise would affect equally both Euclidean distributions 
and the identification of distinct variances for distances of metastatic aneuploidy cells and primary aneuploidy cells would be even more unlikely to be observed by chance.

The hypothesis of a larger variability of the copy number profiles of the metastatic subpopulation is also supported by a closer inspection of the tails of the ploidy distributions of primary and metastatic tumor populations analyzed in Navin et al. ${ }^{16}$. The right-hand sides of the tetraploid peaks for the metastatic tumor have distinctly thicker and longer tails than the corresponding tetraploid peaks in the primary tumor, suggesting greater variability of aneuploidy in the former. Other works point to a similar conclusion. For example, it has been shown recently that, although sharing most of the examined somatic single-nucleotide variants, in vitro cultured low passage melanoma cells have higher copy number variation when compared to the parental tumor ${ }^{67}$.

Ploidy distributions, in their simplicity, offer even more scope for interpretation and testing of the hypothesis that cancer cells have the ability to self-regulate their aneuploidy rate. Indeed, a single cell clone could be capable of generating a diverse metastasis either because of inherent chromosomal instability, or because its rate of aneuploidy is somehow increased under the stress conditions of a new tissue embedding.

Let's assume first that the single clone from the primary tumor has chromosomal instability. The dispersion of metastatic cells should not be in any way preferential to such cells (even if their successful embedding in a tissue may be), so there will be a, possibly small, subpopulation of cells in the primary tumor with similar or higher aneuploidy rate than the cell generating the metastasis. This subpopulation of the primary tumor, by its greater aneuploidy rate, will be more adaptable and likely self-sustaining, and it should be observable as a long tail in the ploidy distribution of the primary tumor population. The tail will be much thinner for the primary tumor than the metastatic tumor, since high aneuploidy rate cells are only a sub-population of the primary tumor. However, no such long and thin tail is observed experimentally for the primary tumor in Navin et al. ${ }^{16}$. It is still possible, if highly unlikely, that the metastatic cell is an extreme outlier, with no comparable cells left in the primary tumor, but then we would see a much more pronounced evolutionary difference between primary and metastatic aneuploid populations than what is observed. This logically implies that the single metastatic cell clone was not essentially different from its primary population before starting to proliferate in the new environment.

This argument leaves only one other option: some cancer cells are capable of altering and self-regulating their aneuploidy rate under stress, or under changes in the environment. In conclusion, both ploidy distribution analysis and single cell analysis of Navin et al. ${ }^{16}$ give strong evidence for the proposition on adaptive aneuploidy in cancer cells presented in the Introduction, i.e. that single clone cancer cells derived from an aneuploid cancer subpopulation, adapt their aneuploid rates in distinct environments, namely primary and metastatic microenvironments.

\section{A diversification factor}

The Discussion, up to now, centered on the inference, from some experimental results of ref. ${ }^{16}$ and other published supportive information ${ }^{48,54,63}$, that metastatic cancer cells have higher aneuploidy rates than the corresponding original subpopulation of the primary tumor. We concluded that this differential could only be explained by assuming an adaptive, self-regulatory cellular response sensitive to changes in the environment. As much as tumor populations undergo extensive evolution during their development, it seems highly unlikely that such a refined property could arise by chance only in the specific population studied in Navin et al. ${ }^{16}$, without a preexisting dormant ability to self-regulation.

Indeed, high levels of aneuploidy are associated with increased adaptability in plants and yeast ${ }^{68,69}$, and a certain rate of aneuploidy, leading to precise percentages of mosaic aneuploidy, is common in several mammals' embryos (see van Soom \& Boerjan ${ }^{70}$ chapter 10), including humans ${ }^{71,72}$. Similarly, it is speculated that the significant mosaic aneuploidy in adult human organs such as the liver and brain is instrumental to an increased plasticity and adaptability of such organs ${ }^{73,74}$. Lang et al. ${ }^{75}$ raise the possibility that the extensive aneuploidy in the embryo may transfer into similarly widespread copy number variations in all human tissues.

Observable levels of aneuploidy have been found in adult cells ${ }^{76}$, and while this widespread aneuploidy could already originate during embryo development ${ }^{75}$, adult, non-transformed stem cells continue to have distinct levels of aneuploidy rates according to their type. For example, mesenchymal stem cells are likely to have very low aneuploidy rates ${ }^{77}$, while hepatocytes together with small intestine and pancreas cells display within-tissue extensive copy number variation $(\mathrm{CNV})^{78,79}$.

These strikingly different aneuploidy rates among embryo stem cells and adult stem cells, raise the possibility that the finely tuned, and distinct, high aneuploidy rates observed in embryos and adult tissues are regulated by some mechanism specific to stem cells, rather than being a simple byproduct of aberrant or sustained cell division. This is a simple, fundamental observation, and yet one that is rarely emphasized in the literature. We formalize its essence in a proposition:

Differentially Expressed Aneuploidy in Stem Cells. Embryo and adult stem cells display finely tuned, and distinct, aneuploidy rates, unrelated to the replication rates of the stem cells themselves.

And we refer to Section 2 of our preprint 'Stem-like Adaptive Aneuploidy and Cancer Quasispecies' (available at arxiv.org/ pdf/1303.6374.pdf) for a much more thorough review of literature supporting the idea of a differentially expressed aneuploidy in stem cells.

Since many types of cancers partially inherit the hierarchical structure of the tissues they have derived from and are assumed to be propagated by stemlike tumor cells ${ }^{80}$, it is possible that increased aneuploidy rates are used actively, to the population advantage, to 
increase the adaptability of stem or fast-dividing progenitor cells. It is worth noting that, to date and to our knowledge, only two studies assessed the relationship between aneuploidy and cancer stem cells (CSCs $)^{81,82}$. In the first paper, Kusumbe and Bapat evaluated the expression of stem-cell markers and the DNA content distribution of fluorescently labeled ovarian cancer cells after subcutaneous injection into immunodeficient mice. The authors found that, unlike label-free tumor cells, the label-retaining (quiescent) cells displayed stem-cell markers and were embedded with a small fraction of aneuploid cells. Treatment with chemotherapy increased the percentage of quiescent cells in the overall population and selectively stimulated the proliferation of the aneuploid fraction, which retained stem-like properties upon removal of the drug ${ }^{81}$. A second study by Fujimori et al., reveals again that stressful conditions favor the emergence of CSC-like clones from differentiating embryo stem cells in in vitro culture ${ }^{82}$.

And this brings us to the proposition we stated in the introduction on adaptive aneuploidy in cancer cells: in light of the refined use of aneuploidy in stem cells, self-regulation of aneuploidy as argued in this Discussion could be a reactivation, in cancer stem cells, of a preexisting cellular mechanism common to embryo and adult stem cells - a diversification factor. Note that the proposition on differentially expressed levels of aneuploidy in normal stem cells is not compatible with a random, self-catalytic increment of aneuploidy first suggested in Rasnick \& Duesby ${ }^{45}$, since otherwise we would not be able to observe consistently similar levels of aneuploidy within each stem cell type, and among different individuals. Moreover, we would see a correlation between fast replicating stem cells and levels of aneuploidy in the corresponding tissue. This is not necessarily the case. For example the percentage of cells undergoing DNA replication in solid tumors, which are mostly aneuploid, varies between $2 \%$ to $8 \%$, whereas a normal renewing epithelium such as the intestine exhibits a DNA replication index of approximately $16 \%^{83}$.

A random progression of aneuploidy would display much more pronounced variability within each stem cell class, while the spread of aneuploidy would be similar in all stem cell classes, and not differentially expressed in each of them. Note that the theory of a self-catalytic origin of aneuploidy in principle could be made consistent with the proposition on adaptive aneuploidy in cancer. It is only by taking together the proposition on adaptive aneuploidy in cancer (stem) cells, and the proposition on differentially expressed aneuploidy in (all) stem cells that we argue the following hypothesis is strongly implied:

A Diversification Factor: There exists a cellular mechanism that regulates adaptation of aneuploidy rates, active, to different degrees and in different modalities, in all embryo, adult and cancer stem cells.

\section{Conclusions}

While it was not the main objective of this theoretical paper to explore the experimental consequences of our hypothesis on adaptive aneuploidy and aneuploid quasispecies, we note that all our statements are open to, indeed they invite, simple forms of validation, either through single cell analysis or ploidy distribution analysis. Elucidating the mechanisms underlying self-regulation of aneuploidy rates in stem cells under specific microenvironmental stresses, would provide crucial insight into the developmental and evolutionary processes of complex organisms.

Finally, we emphasize that validation of the hypothesis that stem cells can adapt their aneuploidy rate through a diversification factor would have significant therapeutical implications, when specialized to cancer stem cells. Indeed, it would provide a biological way, mostly inactive or less sensitive in healthy adult cells, to induce an aneuploid quasispecies error catastrophe to weaken cancer populations, a long held hope that may yet prove itself true.

\section{Author contributions}

DN, MS and DCS conceived the study and carried out the research. DN and MS prepared the first draft of the manuscript. All authors were involved in the revision of the draft manuscript and have agreed to the final content.

\section{Competing interests}

No competing interests were disclosed.

\section{Grant information}

The author(s) declared that no grants were involved in supporting this work.

\section{Acknowledgements}

This paper is dedicated to Rosanna Gonzales. She never ceased to hope.
1. Cooper GM: The cell: a molecular approach. ASM Press, Washington, D.C., 1997; 673. Reference Source

2. Torres EM, Williams BR, Amon A: Aneuploidy: cells losing their balance. Genetics. 2008; 179(2): 737-46. PubMed Abstract | Publisher Full Text | Free Full Text

3. Weaver BA, Silk AD, Montagna C, et al:: Aneuploidy acts both oncogenically and as a tumor suppressor. Cancer Cell. 2007; 11(1): 25-36. PubMed Abstract | Publisher Full Text

4. Pavelka N, Rancati G, Li R: Dr jekyll and Mr Hyde: role of aneuploidy in cellular adaptation and cancer. Curr Opin Cell Biol. 2010; 22(6): 809-15. PubMed Abstract | Publisher Full Text | Free Full Text
5. Kreso A, O'Brien CA, van Galen P, et al.: Variable clonal repopulation dynamics influence chemotherapy response in colorectal cancer. Science. 2013; 339(6119): 543-8.

PubMed Abstract | Publisher Full Text

6. Hasle $\mathrm{H}$, Clemmensen IH, Mikkelsen M: Risks of leukaemia and solid tumours in individuals with Down's syndrome. Lancet. 2000; 355(9199): 165-9. PubMed Abstract | Publisher Full Text

7. Satgé D, Sasco AJ, Lacour B: Are solid tumours different in children with Down's syndrome? Int J Cancer. 2003; 106(2): 297-8.

PubMed Abstract | Publisher Full Text

8. Williams BR, Prabhu VR, Hunter KE, et al.: Aneuploidy affects proliferation and 
spontaneous immortalization in mammalian cells. Science. 2008; 322(5902): 703-9.

PubMed Abstract | Publisher Full Text | Free Full Text

9. McGranahan N, Burrell RA, Endesfelder D, et al:: Cancer chromosomal instability: therapeutic and diagnostic challenges. EMBO Rep. 2012; 13(6): $528-38$.

PubMed Abstract | Publisher Full Text | Free Full Text

10. Landau DA, Carter SL, Stojanov $P$, et al: Evolution and impact of subclonal mutations in chronic lymphocytic leukemia. Cell. 2013; 152(4): 714-26. PubMed Abstract | Publisher Full Text | Free Full Text

11. Sharma SV, Lee DY, Li B, et al.: A chromatin-mediated reversible drug-tolerant state in cancer cell subpopulations. Cell. 2010; 141(1): 69-80.

PubMed Abstract | Publisher Full Text | Free Full Text

12. Workman P, Travers J: Cancer: drug-tolerant insurgents. Nature. 2010; 464(7290): 844-5.

PubMed Abstract | Publisher Full Text

13. Zong C, Lu S, Chapman AR, et al:: Genome-wide detection of single-nucleotide and copy-number variations of a single human cell. Science. 2012; 338(6114): 1622-6.

PubMed Abstract | Publisher Full Text | Free Full Text

14. Owens B: Genomics: The single life. Nature. 2012; 491(7422): 27-9. PubMed Abstract | Publisher Full Text

15. Wang J, Fan HC, Behr B, et al:: Genome-wide single-cell analysis of recombination activity and de novo mutation rates in human sperm. Cell. 2012; 150(2): 402-12.

PubMed Abstract | Publisher Full Text | Free Full Text

16. Navin N, Kendall J, Troge J, et al:: Tumour evolution inferred by single-cell sequencing. Nature. 2011; 472(7341): 90-4. PubMed Abstract | Publisher Full Text

17. Ojosnegros S, Perales C, Mas A, et al:: Quasispecies as a matter of fact: viruses and beyond. Virus Res. 2011; 162(1-2): 203-15.

PubMed Abstract | Publisher Full Text

18. Eigen M: Selforganization of matter and the evolution of biological macromolecules. Naturwissenschaften. 1971; 58(10): 465-523. PubMed Abstract | Publisher Full Text

19. Cahill DP, Kinzler KW, Vogelstein B, et al.: Genetic instability and darwinian selection in tumours. Trends Cell Biol. 1999; 9(12): M57-60. PubMed Abstract | Publisher Full Text

20. Solé RV, Deisboeck TS: An error catastrophe in cancer? J Theor Biol. 2004 228(1): 47-54.

PubMed Abstract | Publisher Full Text

21. Brumer $Y$, Michor F, Shakhnovich El: Genetic instability and the quasispecies model. J Theor Biol. 2006; 241(2): 216-22. PubMed Abstract | Publisher Full Text

22. Diego D, Calvo GF, Pérez-García VM: Modeling the connection between primary and metastatic tumors. J Math Biol. 2013; 67(3): 657-92. PubMed Abstract | Publisher Full Text

23. Itan E, Tannenbaum E: Effect of chromosomal instability on the mutationselection balance in unicellular populations. PLOS One. 2012; 7(5): e26513. PubMed Abstract | Publisher Full Text | Free Full Text

24. Iwami S, Haeno H, Michor F: A race between tumor immunoescape and genome maintenance selects for optimum levels of (epi)genetic instability. PLOS Comput Biol. 2012; 8(2): e1002370.

PubMed Abstract | Publisher Full Text | Free Full Text

25. Michor F, Iwasa $Y$, Nowak MA: Dynamics of cancer progression. Nat Rev Cancer. 2004; 4(3): 197-205.

PubMed Abstract | Publisher Full Text

26. Nowak MA, Michor F, Iwasa Y: Genetic instability and clonal expansion. $J$ Theor Biol. 2006; 241(1): 26-32.

PubMed Abstract | Publisher Full Text | Free Full Text

27. Biebricher CK, Eigen M: The error threshold. Virus Res. 2005; 107(2): 117-27. PubMed Abstract | Publisher Full Text

28. Eigen M, Schuster P: The hypercycle, a principle of natural self-organization. Springer-Verlag, Berlin, 1979; 92. Reference Source

29. Biebricher CK, Eigen M: What is a quasispecies? Curr Top Microbiol Immunol. 2006; 299: 1-31. PubMed Abstract

30. Schuster P: Mathematical modeling of evolution. Solved and open problems. Theory Biosci. 2011; 130(1): 71-89. PubMed Abstract | Publisher Full Text

31. Jenkins GM, Worobey M, Woelk CH, et al:: Evidence for the non-quasispecies evolution of RNA viruses [corrected]. Mol Biol Evol. 2001; 18(6): 987-94. PubMed Abstract

32. Vilar E, Gruber SB: Microsatellite instability in colorectal cancer-the stable evidence. Nat Rev Clin Oncol. 2010; 7(3): 153-62. PubMed Abstract | Publisher Full Text | Free Full Text

33. de la Chapelle A, Hampel $\mathrm{H}$ : Clinical relevance of microsatellite instability in colorectal cancer. J Clin Oncol. 2010; 28(20): 3380-7. PubMed Abstract | Publisher Full Text | Free Full Text
34. Alberts B, Wilson JH, Hunt T: Molecular biology of the cell. Garland Science, New York, 5th ed., reference ed edition, 2008; 1392.

Reference Source

35. Gundry M, Vijg J: Direct mutation analysis by high-throughput sequencing: from germline to low-abundant, somatic variants. Mutat Res. 2012; 729(1-2): $1-15$.

PubMed Abstract | Publisher Full Text | Free Full Text

36. Lange SS, Takata K, Wood RD: DNA polymerases and cancer. Nat Rev Cancer. 2011; 11(2): 96-110.

PubMed Abstract | Publisher Full Text | Free Full Text

37. Jiricny J: The multifaceted mismatch-repair system. Nat Rev Mol Cell Biol. 2006; 7(5): 335-46.

PubMed Abstract | Publisher Full Text

38. Gordon DJ, Resio B, Pellman D: Causes and consequences of aneuploidy in cancer. Nat Rev Genet. 2012; 13(3): 189-203.

PubMed Abstract | Publisher Full Text

39. Beroukhim R, Mermel CH, Porter D, et al.: The landscape of somatic copynumber alteration across human cancers. Nature. 2010; 463(7283): 899-905. PubMed Abstract | Publisher Full Text | Free Full Text

40. Albertson DG: Gene amplification in cancer. Trends Genet. 2006; 22(8): 447-55 PubMed Abstract | Publisher Full Text

41. Gajduskova P, Snijders AM, Kwek S, et al:: Genome position and gene amplification. Genome Biol. 2007; 8(6): R120. PubMed Abstract | Publisher Full Text | Free Full Text

42. Santarius T, Shipley J, Brewer D, et al.: A census of amplified and overexpressed human cancer genes. Nat Rev Cancer. 2010; 10(1): 59-64. PubMed Abstract | Publisher Full Text

43. Chen G, Rubinstein B, Li R: Whole chromosome aneuploidy: big mutations drive adaptation by phenotypic leap. Bioessays. 2012; 34(10): 893-900. PubMed Abstract | Publisher Full Text | Free Full Text

44. Sheltzer JM, Amon A: The aneuploidy paradox: costs and benefits of an incorrect karyotype. Trends Genet. 2011; 27(11): 446-53. PubMed Abstract | Publisher Full Text | Free Full Text

45. Rasnick D, Duesberg PH: How aneuploidy affects metabolic control and causes cancer. Biochem J. 1999; 340((Pt 3): 621-30.

PubMed Abstract | Publisher Full Text | Free Full Text

46. Pavelka N, Rancati G, Zhu J, et al:: Aneuploidy confers quantitative proteome changes and phenotypic variation in budding yeast. Nature. 2010; 468(7321): 321-5.

PubMed Abstract | Publisher Full Text | Free Full Text

47. $\mathrm{Xu} X$, Hou $Y$, Yin $X$, et al.: Single-cell exome sequencing reveals singlenucleotide mutation characteristics of a kidney tumor. Cell. 2012; 148(5): 886-95.

PubMed Abstract | Publisher Full Text

48. Gerlinger M, Rowan AJ, Horswell S, et al:: Intratumor heterogeneity and branched evolution revealed by multiregion sequencing. N Engl J Med. 2012; 366(10): 883-92.

PubMed Abstract | Publisher Full Text

49. Campbell PJ, Yachida S, Mudie LJ, et al.: The patterns and dynamics of genomic instability in metastatic pancreatic cancer. Nature. 2010; 467(7319): 1109-13. PubMed Abstract | Publisher Full Text | Free Full Text

50. Shah SP, Roth A, Goya R, et al:: The clonal and mutational evolution spectrum of primary triple-negative breast cancers. Nature. 2012; 486(7403): 395-9. PubMed Abstract | Publisher Full Text

51. Caldas C: Cancer sequencing unravels clonal evolution. Nat Biotechnol. 2012; 30(5): 408-10

PubMed Abstract | Publisher Full Text

52. Bakhoum SF, Compton DA: Chromosomal instability and cancer: a complex relationship with therapeutic potential. $J$ Clin Invest. 2012; 122(4): 1138-43. PubMed Abstract | Publisher Full Text | Free Full Text

53. Vogt N, Lefèvre $\mathrm{SH}$, Apiou $\mathrm{F}$, et al:: Molecular structure of double-minute chromosomes bearing amplified copies of the epidermal growth facto receptor gene in gliomas. Proc Natl Acad Sci U S A. 2004; 101(31): 11368-73. PubMed Abstract | Publisher Full Text | Free Full Text

54. Turajlic S, Furney SJ, Lambros MB, et al.: Whole genome sequencing of matched primary and metastatic acral melanomas. Genome Res. 2012; 22(2): 196-207. PubMed Abstract | Publisher Full Text | Free Full Text

55. Lengauer C, Kinzler KW, Vogelstein B: Genetic instability in colorectal cancers. Nature. 1997; 386(6625): 623-7. PubMed Abstract | Publisher Full Text

56. Rajagopalan $\mathrm{H}$, Nowak MA, Vogelstein $\mathrm{B}$, et al:: The significance of unstable chromosomes in colorectal cancer. Nat Rev Cancer. 2003; 3(9): 695-701. PubMed Abstract | Publisher Full Text

57. Burns EM, Christopoulou L, Corish P, et al:: Quantitative measurement of mammalian chromosome mitotic loss rates using the green fluorescent protein. J Cell Sci. 1999; 112((Pt 16): 2705-14. PubMed Abstract

58. Camps J, Ponsa I, Ribas M, et al:: Comprehensive measurement of chromosomal instability in cancer cells: combination of fluorescence in situ hybridization and cytokinesis-block micronucleus assay. FASEB J. 2005; 19(7): 
$828-30$

PubMed Abstract | Publisher Full Text

59. Lee AJ, Endesfelder D, Rowan AJ, et al.: Chromosomal instability confers intrinsic multidrug resistance. Cancer Res. 2011; 71(5): 1858-70.

PubMed Abstract | Publisher Full Text | Free Full Text

60. Duesberg P, Stindl R, Hehlmann R: Origin of multidrug resistance in cells with and without multidrug resistance genes: chromosome reassortments catalyzed by aneuploidy. Proc Natl Acad Sci U S A. 2001; 98(20): 11283-8. PubMed Abstract | Publisher Full Text | Free Full Text

61. Bakhoum SF, Danilova OV, Kaur P, et al.: Chromosomal instability substantiates poor prognosis in patients with diffuse large B-cell lymphoma. Clin Cancer Res. 2011; 17(24): 7704-11.

PubMed Abstract | Publisher Full Text | Free Full Text

62. Hou $Y$, Song L, Zhu P, et al:: Single-cell exome sequencing and monoclonal evolution of a JAK2-negative myeloproliferative neoplasm. Cell. 2012; 148(5): 873-85.

PubMed Abstract | Publisher Full Text

63. Wu X, Northcott PA, Dubuc A, et al.: Clonal selection drives genetic divergence of metastatic medulloblastoma. Nature. 2012; 482(7386): 529-33.

PubMed Abstract | Publisher Full Text | Free Full Text

64. Clifford SC: Cancer genetics: Evolution after tumour spread. Nature. 2012; 482(7386): 481-2.

PubMed Abstract | Publisher Full Text

65. Klein CA: Parallel progression of primary tumours and metastases. Nat Rev

Cancer. 2009; 9(4): 302-12.

PubMed Abstract | Publisher Full Text

66. Schultz BB: Levene's test for relative variation. Syst Biol. 1985; 34(4): 449-456. Publisher Full Text

67. Parker SC, Gartner J, Cardenas-Navia I, et al.: Mutational signatures of dedifferentiation in functional non-coding regions of melanoma genomes. PLoS Genet. 2012; 8(8): e1002871.

PubMed Abstract | Publisher Full Text | Free Full Text

68. te Beest M, Le Roux JJ, Richardson DM, et al:: The more the better? the role of polyploidy in facilitating plant invasions. Ann Bot. 2012; 109(1): 19-45. PubMed Abstract | Publisher Full Text | Free Full Text

69. Chen G, Bradford WD, Seidel CW, et al:: Hsp90 stress potentiates rapid cellular adaptation through induction of aneuploidy. Nature. 2012; 482(7384): 246-50. PubMed Abstract | Publisher Full Text | Free Full Text

70. van Soom A, Boerjan M: Assessment of mammalian embryo quality: invasive and non-invasive techniques. Kluwer Academic Publishers, Dordrecht, 2002; 406. Reference Source
71. Ledbetter DH: Chaos in the embryo. Nat Med. 2009; 15(5): 490-1. PubMed Abstract | Publisher Full Text

72. Peterson SE, Westra JW, Rehen SK, et al:: Normal human pluripotent stem cell lines exhibit pervasive mosaic aneuploidy. PLoS One. 2011; 6(8): e23018. PubMed Abstract | Publisher Full Text | Free Full Text

73. Duncan AW, Hanlon Newell AE, Bi W, et al:: Aneuploidy as a mechanism for stress-induced liver adaptation. J Clin Invest. 2012; 122(9): 3307-15. PubMed Abstract | Publisher Full Text | Free Full Text

74. Rehen SK, Yung YC, McCreight MP, et al.: Constitutional aneuploidy in the normal human brain. J Neurosci. 2005; 25(9): 2176-80. PubMed Abstract | Publisher Full Text

75. Liang Q, Conte N, Skarnes WC, et al:: Extensive genomic copy number variation in embryonic stem cells. Proc Natl Acad Sci U S A. 2008; 105(45): 17453-6. PubMed Abstract | Publisher Full Text | Free Full Text

76. Abyzov A, Mariani J, Palejev D, et al.: Somatic copy number mosaicism in human skin revealed by induced pluripotent stem cells. Nature. 2012; 492(7429): 438-42.

PubMed Abstract | Publisher Full Text | Free Full Text

77. Grimes BR, Steiner CM, Merfeld-Clauss S, et al:: Interphase fish demonstrates that human adipose stromal cells maintain a high level of genomic stability in long-term culture. Stem Cells Dev. 2009; 18(5): 717-24. PubMed Abstract | Publisher Full Text | Free Full Text

78. Duncan AW, Taylor MH, Hickey RD, et al:: The ploidy conveyor of mature hepatocytes as a source of genetic variation. Nature. 2010; 467(7316): 707-10. PubMed Abstract | Publisher Full Text | Free Full Text

79. O'Huallachain M, Karczewski KJ, Weissman SM, et al.: Extensive genetic variation in somatic human tissues. Proc Natl Acad Sci U S A. 2012; 109(44): 18018-23.

PubMed Abstract | Publisher Full Text | Free Full Text

80. Nguyen LV, Vanner R, Dirks $P$, et al.: Cancer stem cells: an evolving concept. Nat Rev Cancer. 2012; 12(2): 133-43. PubMed Abstract | Publisher Full Text

81. Kusumbe AP, Bapat SA: Cancer stem cells and aneuploid populations within developing tumors are the major determinants of tumor dormancy. Cancer Res. 2009; 69(24): 9245-53. PubMed Abstract | Publisher Full Text

82. Fujimori $\mathrm{H}$, Shikanai $\mathrm{M}$, Teraoka $\mathrm{H}$ : Induction of cancerous stem cells during embryonic stem cell differentiation. J Biol Chem. 2012; 287(44): 36777-91. PubMed Abstract | Publisher Full Text | Free Full Text

83. Tannock I, Hill RP: The Basic science of oncology. Pergamon Press, New York, 1987; 398 Reference Source 


\section{Open Peer Review}

\section{Current Peer Review Status:}

\section{Version 1}

Reviewer Report 10 March 2014

https://doi.org/10.5256/f1000research.2944.r4034

(C) 2014 Bakhoum S. This is an open access peer review report distributed under the terms of the Creative Commons Attribution License, which permits unrestricted use, distribution, and reproduction in any medium, provided the original work is properly cited.

\section{Samuel F Bakhoum}

Mount Auburn Hospital, Harvard Medical School, Boston, MA, USA

In this interesting opinion article, Napoletani et al. attempt to apply the quasispecies theory to the evolution of anueploidy in cancer. This article proposes some interesting points that attempt to address the origin of genetic heterogeneity in tumors. An important claim made therein is that aneuploidy is likely to be the major source of genetic heterogeneity in later stages of tumor development particularly when compared to the rate of individual DNA mutations. Further, the authors also posit that cancer cells must maintain a given rate of chromosome missegregation beyond which a meltdown occurs.

I think this article is acceptable, but feel the authors should address the following points:

Please change the "aneuploidy rate" into "chromosome mis-segregation rate" or something of that nature. Aneuploidy by definition is a state and not a rate. What the authors imply is "the rate of change in aneuploid karyotypes which is synonymous to chromosome missegregation (which includes whole chromosome missegregation as well as partial i.e. translocation etc...)

It is important throughout the article to make the distinction between tolerance for aneuploidy in normal vs. cancer tissues. While evidence suggests that aneuploidy may lead to cellular stress in normal tissues, it is unclear whether this is the case in cancer cells. Either cancer cells preferentially maintain aneuploidy at the expense of increased cellular stress and slower proliferation rate or they might instead have also evolved to overcome cellular stress in response to aneuploidy. Furthermore, constitutional aneuploidy (for instance in individuals with trisomy) may have gone through a stem-cell adaptation phase that is different when compared to cancer cells who acquire aneuploidy de novo.

The concept of error catastrophe is very interesting and rather important in the field of aneuploidy and chromosome segregation. I would encourage the authors to further elaborate on the optimal $\mathrm{T}(\mathrm{Em})$ value being near $10^{-2}$. Can the authors use the quasispecies model to make predictions for the fitness of the tumor cell populations if the $T(E m)$ values were much higher? This would be extremely valuable. 
In addition to chromosome segregation errors (which include whole and partial chromosome copy number changes) it would be useful to incorporate the newly uncovered massive rearrangements known as chromothripsis and chromoplexy. In some cases, these massive rearrangements can lead to double minute chromosomes carrying oncogenes that are present in hundreds of copies (a lot higher than the maximum rate of 20 copies for any given gene that the authors presume). The authors do not account for these possibilities in their model.

A concept that the authors bring up is the presence of a feedback loop from the environment that can "fine tune" chromosome segregation. While there is no data to necessarily refute this assumption, this reviewer believes that it is not currently supported by experimental data. What is much more likely is that mis-segregation rates occur somewhat independently and aneuploid cells are under constant selection in vivo which may ultimately favor cells that have a given missegregation rate to become more viable under certain conditions.

Competing Interests: No competing interests were disclosed.

\section{I confirm that I have read this submission and believe that I have an appropriate level of expertise to confirm that it is of an acceptable scientific standard.}

Reviewer Report 30 December 2013

https://doi.org/10.5256/f1000research.2944.r2916

(C) 2013 Gordeladze J. This is an open access peer review report distributed under the terms of the Creative Commons Attribution License, which permits unrestricted use, distribution, and reproduction in any medium, provided the original work is properly cited.

\section{Jan Oxholm Gordeladze}

Institute of Basic Medical Sciences, Faculty of Medicine, University of Oslo, Oslo, Norway

The authors emphasize in their introduction to the present paper that: "The theoretical frame to understand such self-regulation resides with quasispecies theory", however, they introduce a change in its definition or the meaning of its objects. In particular, they propose a novel definition of the chromosomal master sequence. Finally, they discuss the potential origin of this self-regulatory ability in the wider context of developmental and comparative biology with emphasis on a putative "diversification factor", defined as a cellular mechanism regulating the adaptation of aneuploidy rates, which is active in all embryonic and adult cells, as well as cancer stem cells. Furthermore, they refer to literature asserting that single clone cancer cells derived from an aneuploid cancer subpopulation, are capable of adapting their aneuploidy rate, and they display distinct aneuploid rates in distinct environments, namely primary and metastatic microenvironments.

This literature survey indicates that embryonic and adult stem cells display finely tuned, and distinct, aneuploidy rates, which are unrelated to the replication rates of the stem cells in question. Since many types of cancer cells partially inherit the hierarchical structure of the tissues 
from which they emanate, and are hypothesized to develop from stem like tumor cells, it seems highly probable that increased aneuploidy rates are used as an advantage to a given cell population, e.g. to increase the adaptability of stem or fast-dividing progenitor cells.

In this article the authors introduce the concept of a "diversification factor", which is probably the key issue of the article. This factor may as well be extended to a cluster of "impacting signals", which may fit the modern definition of epigenetics, encompassing signals defined as "epigenators", "initiators" and "maintainers", of which transcription factors (TFs), microRNAs and histone modifying enzymes (like histone deacetylases = HDACS) are known to play important parts, since they constitute a strongly interwoven network with feed-forward-and feed-back regulatory loops.

This network is under the influence of environmental/positional "factors" (epigenators, e.g. surface molecules, mechanical stimulation, environmental chemicals and others) recognized by the "initiators/maintainers" (e.g. TFs and microRNAs), and most importantly, this regulatory web is common to embryonic cells, stem cells, cancer stem cells, and adult (i.e. differentiated) cells. It is therefore highly probable that the degree of aneuploidy of cancer cells is highly dependent on environmental phenomena, and not solely on intrinsic or "inherited" traits localized within the cancerous cells themselves.

Competing Interests: No competing interests were disclosed.

\section{I confirm that I have read this submission and believe that I have an appropriate level of expertise to confirm that it is of an acceptable scientific standard.}

The benefits of publishing with F1000Research:

- Your article is published within days, with no editorial bias

- You can publish traditional articles, null/negative results, case reports, data notes and more

- The peer review process is transparent and collaborative

- Your article is indexed in PubMed after passing peer review

- Dedicated customer support at every stage

For pre-submission enquiries, contact research@f1000.com

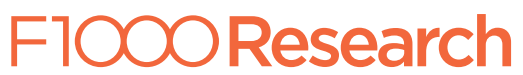

